\title{
Water use efficiency, plant growth and vegetative traits of rubber (Hevea brasiliensis) seedlings grown using different growing media and water levels
}

\author{
Monsuru Adekunle Salisu ${ }^{1 *}$, Zulkefly Sulaiman ${ }^{2}$, Ridzwan Che Rus ${ }^{2}$, Mohd Yusoff A. Samad ${ }^{3}$, Norhanizan \\ Usaizan $^{3}$, Yusuff Oladosu ${ }^{3}$ and Paiman ${ }^{4}$
}

\author{
${ }^{1}$ Department of Agricultural Science, Faculty of Technical and Vocational, Sultan Idris Education University 35900 \\ Tanjung Malim, Perak, Malaysia \\ ${ }^{2}$ Institute of plantation studies, Universiti Putra Malaysia, 43400 UPM Serdang, Selangor, Malaysia \\ ${ }^{3}$ Institute of Tropical Agriculture and Food Security, Universiti Putra Malaysia (UPM), UPM, Serdang 43400, Malaysia \\ ${ }^{4}$ Department of Agrotechnology, Faculty of Agriculture, Universitas PGRI Yogyakarta, JI. PGRI Sonosewu no. 117, \\ Yogyakarta, Indonesia
}

*Corresponding author: salisu@ftv.upsi.edu.my

\begin{abstract}
The aim of this study was to evaluate the effects of soilless media and water levels on growth and physiological response of rubber plant. The four water levels were $150: 50 \%, 175: 75 \%, 1100: 100 \%$ and $1150: 150 \%$ ) with three replications per water treatment and four soilless media. Water levels were determined as irrigation needed for the root zone in growing media to rise to field capacity I100:100\%, at field capacity (FC). The experiment was laid out in randomized complete block design (RCBD) in factorial arrangement $3 \mathrm{x}$ 4 with three replications. Soilless medium contains proportion of vermiculite, perlite, coconut husk, empty fruit bunch (EFB) compose, Christmas Island Rock Phosphate (CIRP), peat moss, urea-N and burnt rice husk coded as M1. Vermiculite, perlite, coconut husk, EFB, CIRP, peat moss, urea-N, sugarcane bagasse coded as M2. M3 is a commercial soilless medium and $100 \%$ soil was designated as control. The M1 significantly influenced almost all plant growth traits, noticeable in biomass production. Growth of plants in M1 corresponded to higher water use efficiency WUEinstantaneous and WUEintrinsic, the M1 increased plant growth like LAR, biomass production and root morphological traits. Shoot dry weight of the plant was greater $(14.66 \mathrm{~g} / \mathrm{plant})$ when $150 \%$ was applied and significantly different from M2 (10.36 g/plant), M3 (4.73 g/plant) and M4 $6.22 \mathrm{~g} /$ plant. Lower water level 50\%, applied in plant grown in M1 (31.94 g/plant) recorded highest total shoot fresh weight (SFW). The results showed suitability of the soilless medium M1 and the $50 \%$ water level for rubber nursery planting. Consequently, it is recommended for planting where management and control of irrigation water are considered necessary in rubber plantation.
\end{abstract}

Keywords: Growing media; Rubber; Vegetative traits; Water use efficiency; Seedlings.

Abbreviations: CIRP_Christmas Island Rock Phosphate; EFB_Empty Fruit Bunch; WUE_Water Use Efficiency; FC_Field Capacity; LAR_Leaf Apperance Rate; SFW_Shoot Fresh Weight.

\section{Introduction}

The demand for rubber has led to the planting of rubber in marginal areas, such as dry areas. Water quality and its scarcity has been recorded in many parts of the world (Fuller and Harhay, 2010). Shortage of freshwater has been categorized as one of the most severe agricultural challenges, resulting in saline and dry lands which reduces crop yield (Moshlion et al., 2015). Through transpiration, seedlings use about 400 to $700 \mathrm{~g}$ (14 to $25 \mathrm{oz}$ ) water to enable the production of a reasonable amount of biomass through photosynthesis. This aids cell enlargement as a result of positive pressure which cools leaf surface through transpiration and photosynthetic process. Characteristics of successful seedlings for replanting have been based on morphology, physiology, and chemical characteristics.
Soilless substrates are preferred to soils by many growers due to its superior physical and hydraulic characteristics. This is because plants grown in soils only experience higher moisture immediately after irrigation. During this time microspores are filled with water followed by a proportional slow drainage and inadequate oxygen compared to the requirement of soil microflora and plant roots unlike substrate or soilless which simultaneously optimize both water and oxygen availability for plant growth (Lieth and Oki, 2008). Colombo et al., (2001) reported that water availability determines and regulates morphology, physiological traits and genetic components of seedlings. 
Excess water supply should be avoided. For example in some of the traditional rubber growing areas, irrigation at $50 \%$ of the crop evapotranspiration may be enough to increase plant growth (Jessy et al., 1996). Apart from the physiological changes plant equally experience negative morphological changes under excessive watering. A number of nursery managers often excessively water plants and thereby face cost issues due to overwatering (Carles et al., 2005) However, the sensitivity of Hevea especially at immature or seedling stage to an excessive water supply which severely destroyed tree had been reported by Penot and Lecomte, (2002). The hypotheses for this experiment were that soilless media help (1) to retain moisture for efficient water use by plants (2) physical properties of soilless aids root penetration and increase growth and total biomass production. This work relies on the previous studies indicating lower drainage and poor aeration of many of the tropical soils which causes poor growth of plants.

\section{Results}

\section{Physicochemical properties of growing media}

The $\mathrm{pH}$ of the media ranged between $\mathrm{M} 1(5.48 \pm 0.01), \mathrm{M} 2$ $(5.22 \pm 0.01), \mathrm{M} 3(6.42 \pm 0.03)$ and M4 $(4.20 \pm 0.06)$ soil (Table 1). The soil recorded the lowest $\mathrm{pH}$ plants indicated it is acidic. The soilless medium (M3) had the highest $\mathrm{pH}$. Nevertheless, the $\mathrm{pH}$ values, especially for the $\mathrm{M} 1$ and $\mathrm{M} 2$, could be considered optimum and it is suitable for many crops under greenhouse. The electrical conductivity (EC) recorded in all the growing media were suitable for the plant growth. The C: $N$ ratio ranges between $13.67 \pm 0.88$ and $21.00 \pm 0.58$, however, M4 soil-based medium had the lowest while soilless media M1 and $\mathrm{M} 2$ had considerably suitable values for adequate plant growth. The soil M4 (control) equally recorded the lowest $(1.50 \pm 0.06 \%)$ total organic carbon (TOC) content while M1 (12.97 $\pm 0.27 \%), M 2(22.27 \%)$ and M 3 (15.83 $\pm 0.52 \%)$. The $N$ was mostly present as organic $\mathrm{N}$ in the soil while $\mathrm{N}$ in soilless

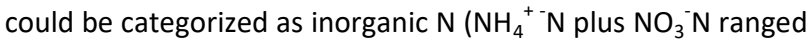
from $4.10 \pm 0.06$ to $6.47 \pm 0.34 \mathrm{~g} \mathrm{~kg}^{-1}$ ).

The extractable concentrations of base cations $\left(\mathrm{Ca}^{+}, \mathrm{K}^{+}, \mathrm{Mg}^{2+}\right)$ for the soilless potting mix and soil shows that concentrations of these elements are higher than what was found in soil. This was evident in the amount of cation exchange capacity recorded in each of the media. The soilless medium M1 had the highest C.E.C $(43.63 \pm 0.72 \mathrm{cmol} / \mathrm{kg})$ followed by the second new medium M2 with $(39.39 \pm 0.61 \mathrm{cmol} / \mathrm{kg})$ and $\mathrm{M} 3$ commercial-based medium $(34.77 \pm 0.61 \mathrm{cmol} / \mathrm{kg})$ while the soil had the lowest $(20.50 \pm 0.6 \mathrm{cmol} / \mathrm{kg})$. Also, there was presence of negligible heavy metals in the soilless media.

\section{Plant growth characteristics}

The results showed significant effect of growing media on a number of leaves and leaf appearance rate Fig. $1 a$ and $b$. Based on $50 \%$ water regime, there was a significant difference among growing media in relation to plant height, number of leaf and leaf appearance rates. There were significant differences between plants grown in $M 4(48.3 \mathrm{~cm})$ soil and plants grown in $\mathrm{M} 2(35 \mathrm{~cm})$ and $\mathrm{M} 3(33.66 \mathrm{~cm})$. There was a significant difference between plants grown in these media and $\mathrm{M} 3(33 \mathrm{~cm})$ commercial medium. But the interaction between $100 \%$ water regime and soilless media showed a significant increase of plant height in $M 3(50 \mathrm{~cm})$ and significantly different from plants grown in $M 1(36 \mathrm{~cm})$ and $M 2$ $(34 \mathrm{~cm})$. But there was a significant difference between plants grown in $\mathrm{M} 1$ and $\mathrm{M} 3(2.7 \mathrm{~mm})$. The interaction between growing media and $75 \%$ water level indicated a significant increase in growth of plants grown in $\mathrm{M} 2$ (3.9 mm) but not significantly different from what recorded in $\mathrm{M} 1(3.24 \mathrm{~mm})$ then significantly greater than plants grown in $\mathrm{M} 3(2.74 \mathrm{~mm})$ and M4 $(3.2 \mathrm{~mm})$. Interaction between the media and $100 \%$ water levels showed a significant increase of plant stem diameter in plants grown in $M 3(4.1 \mathrm{~mm})$ but was not significantly different from plants grown in M4 $(3.48 \mathrm{~mm})$ but the value was greater and significantly different from plants grown in $\mathrm{M} 1$ (3.27 $\mathrm{mm})$ and $\mathrm{M} 2(3.13 \mathrm{~mm})$. The highest water regime $150 \%$ showed an increase plant stem diameter in $M 1$ $(4.58 \mathrm{~cm})$ and significantly different from plants grown in $M 3$ $(3.63 \mathrm{~mm})$ and M4 $(3.67 \mathrm{~mm})$. The results indicated higher LAR in plants grown in $\mathrm{M} 1$ and significantly different from plants grown in $\mathrm{M} 2$ as shown in Fig $2 \mathrm{a}$ and $\mathrm{b}$. Then plants grown in $\mathrm{M} 2$ were significantly different from plants grown in $\mathrm{M} 3$ and M4 which recorded lower values.

\section{Plant biomass yield}

There was a significant difference between the root fresh weight of plants grown in M1 (14.17 g/plant) and M2 (3.79 $\mathrm{g} /$ plant) and M3 (6.22 g/plant) and the $50 \%$ water level Fig. 3a and $b$. The highest value was recorded in M1. The interaction between soilless media and $75 \%$ water regime indicated a sharp increase in root fresh weight of plants grown in M2 (9.47 $\mathrm{g} /$ plant) and significantly different from plants grown in $\mathrm{M} 3$ (3.81 g/plant) and M4 (6.14 g/plant). Root fresh weight of the plants grown in M1 was significantly different from M4 $(8.50$ $\mathrm{g} /$ plant) soil. Application of highest water regime $150 \%$, equally shows that root fresh weight of plants grown in $\mathrm{M} 1$ (20.47 g/plant) was greater than those in M4 (8.9 g/plant) soil. But M1 was not significantly different from M2 (13.68 g/plant) and M3 (11.47 g/plant). Interaction between water at inception of water regimes showed that M1 (2.72 g/plant) positively responded to water control at $50 \%$ as the root dry weight significantly different from plants grown in M2 (0.67 $\mathrm{g} /$ plant) and M3 $(0.97 \mathrm{~g} /$ plant $)$. However, the interaction between the soilless media and the water level at $75 \%$ indicated that the plants that were grown in M2 (2.93 g/plant) showed an increasing root dry weight and significantly different from what was obtained in M1 (1.8 g), M3 (0.67 $\mathrm{g} /$ plant) and M4 (1.65 g/plant). The value obtained in plants grown in M1 (3.70 g/plant) was greater and significantly different from M3 (1.89 g/plant) commercial medium when highest water level $150 \%$ was applied.

Shoot fresh weight of the plants grown in newly produced soilless media M1 (17.77 g/plant) and M2 17.42 including M4 (14.56 g/plant) significantly different from M3 (5.53 g/plant) commercial based soilless medium when water level at $50 \%$ was applied (Fig. 4a and b). Interaction between the soilless media and water regime at $75 \%$ showed a significant difference between M2 (23.73 g/plant), M3 (5.70 g/plant) and M4 (10.38 g/plant). Soilless media interactions with $150 \%$ water level shows shoot fresh weight of plants grown in M1 
(29.84 g/plant) and M2 (26.39 g/plant) was greater and significantly different from plants grown in M3 (12.45 g/plant) and M4 (13.04 g/plant). Shoot dry weight of the plants grown in newly produced media M1 $(8.20 \mathrm{~g} /$ plant) and M2 (6.02 $\mathrm{g} /$ plant) including M4 (6.12 $\mathrm{g} / \mathrm{plant})$ were greater and significantly different from M3 $(5.53 \mathrm{~g} /$ plant) commercial based soilless medium. Interaction effect of soilless media and water level at $75 \%$ shows an increasing dry weight in $\mathrm{M} 2$ $(10.88 \mathrm{~g} / \mathrm{plant})$ and significantly different from plants grown in M1 (6.23 g/plant), M3 (2.02 g/plant) and M4 (4.4 g/plant). Shoot dry weight greatly increased on M1 (14.66 g/plant) when $150 \%$ water regime was applied and significantly different from M2 (10.36 g/plant), M3 (4.73 g/plant) and M4 (6.22 g/plant).

The interaction between soilless media and water regime at $50 \%$ showed plants grown in M1 $(31.94 \mathrm{~g} /$ plant) recorded highest total shoot fresh weight and significantly different from M2 (21.22 g/plant) M3 (11.76 g/plant) and M4 (21.82 g/plant) (Fig. $5 a$ and b). Similar values and significant differences were recorded when $75 \%$ water level was applied. Noticeably, the interaction between soilless media and water regime at $150 \%$ shows that $\mathrm{M} 1(50.31 \mathrm{~g} /$ plant $)$ increases total fresh weight and significantly different from M3 (22.32 $\mathrm{g} /$ plant) and M4 (21.94 g/plant)

The total dry weight of plants grown in M1 (10.93 g/plant), M2 (6.69 g/plant), M4 (7.99 g/plant) was significantly different from M3 (3.09 g/plant) on water level at 50\%. After application of $75 \%$ water level, the total dry weight of plants grown in M2 (13.82 g/plant) increased and significantly different from plants grown in M1 (8.03 g/plant), M3 (2.69 $\mathrm{g} /$ plant) and M4 (5.95 g/plant). Noticeably, interaction between the media and the water regime at $150 \%$ shows $M 1$ (18.36 g/plant) increases total dry weight and significantly different from M2 (12.78 g/plant), M3 (6.63 g/plant) and M4 $(8.97 \mathrm{~g} /$ plant $)$.

\section{Water use efficiency (WUE)}

The interaction between growing media and water regimes on plant water use efficiency was significant at $p<0.01$. The interaction between media and water regime at $75 \%$ shows there were significant differences among the plants grown in the respective media with highest water use efficiency in plants grown in $\mathrm{M} 1$ (0.423) than those in $\mathrm{M} 2(0.24), \mathrm{M} 3(0.21)$ and M4 (0.31) as shown in Fig. 6a and b. Also, there was a significant difference between plants grown in M4 and M3 while $\mathrm{M} 2$ recorded the lowest WUEinstantaneous. There was an increase in the WUE of the seedlings that were grown in $\mathrm{M} 2$ (0.36) after application of $100 \%$ water level and significantly different from plants grown in M1 (0.29), M3 0.20 and M4 0.24 . However, WUE of plants grown in $\mathrm{M} 1$ efficiently utilized water and significantly different from plants grown in $\mathrm{M} 3$ and M4. Water use efficiency of plants grown in M1 noticeably increased (1.49) after application of the highest water level $150 \%$ and significantly different from plants grown in $M 2$ (0.31), M3 (0.29) and M4 (0.21). The interaction between soilless media and water regime at $75 \%$ shows there were significant differences among the plants grown in the respective soilless media with highest water use efficiency recorded in plants grown in $\mathrm{M} 1$ (3.39) than those in $\mathrm{M} 2$ (2.15), M3 (1.32) and M4 (2.45).

There was a significant difference between plants grown in M4 and $M 3$ while $M 2$ recorded the lowest $W_{U} E_{\text {intrinsic }}$. There was an increased water use of plants grown in M2 (2.62) after application of $100 \%$ water level and significantly different from plants grown in M1 (2.09), M3 (1.26) and M4 (1.72). Plants grown in $\mathrm{M} 1$ efficiently utilized water and significantly different from plants grown in M3 and M4. Noticeably, plants grown in $\mathrm{M} 1$ efficiently utilized water after application of the highest water level $150 \%$ and significantly different (6.62) from M2 (2.39), M3 (2.37) and M4 (1.39).

\section{Root morphology}

Root length of the plants grown in $\mathrm{M} 1(2501.7 \mathrm{~cm})$ and $50 \%$ water level was significantly different from M4 $(136 \mathrm{~cm})$ soil (Fig. 7a and b). Furthermore, the interaction between media and water at $75 \%$ shows an increase of plant root in M1 2373 $\mathrm{cm}$ ) and significantly different from root length of plants grown in M2 $(1742 \mathrm{~cm}), \mathrm{M} 3(316.8 \mathrm{~cm})$ and M4 $(456.83 \mathrm{~cm})$. Noticeably, the trend shows a decrease of root length after application of $100 \%$ and no significant differences were observed among the soilless media. Interestingly, after the application of $150 \%$ water level, root length of the plants significantly increased. There were significant differences in root volume of plants grown in soilless media and $50 \%$ water whereby plants grown in $\mathrm{M} 1\left(8.69 \mathrm{~cm}^{3}\right)$ recorded higher root volume and significantly different from plants in M2 (4.53 $\left.\mathrm{cm}^{3}\right), \mathrm{M} 3\left(5.06 \mathrm{~cm}^{3}\right)$ and M4 $\left(1.99 \mathrm{~cm}^{3}\right)$. There were significant differences in root volume of plant grown in $M 2\left(6.45 \mathrm{~cm}^{3}\right)$, M1 $\left(3.92 \mathrm{~cm}^{3}\right)$ and $M 3\left(1.11 \mathrm{~cm}^{3}\right)$. The interaction between soilless media and $100 \%$ water level shows a tremendous increase of root volume of plants grown in $M 1\left(7.74 \mathrm{~cm}^{3}\right)$ and significantly different from plants grown in $M 3\left(4.69 \mathrm{~cm}^{3}\right)$ and M4 $\left(3.85 \mathrm{~cm}^{3}\right)$. Interaction effects of the soilless and soil-based and water levels was noticed on root patterns (Fig. 8a, b, c and d).

\section{Discussio}

The results indicated significant differences between the soilless media and the soil in term of moisture retention capacity as shown in almost all the parameters measured especially in the new media. This could have been due to the materials composition like sugarcane bagasse, and coconut husk. Hussain et al., (2014), noted that a well-formulated soilless media using right substrate composition could efficiently retain moisture and fertilizer when compared to soil. Some of the soils used in nursery plantation have low water permeability due to high clay. This is supported by Spomer, (1975). Plant height and stem diameter responded differently, noticeably in $\mathrm{M} 1$ and $\mathrm{M} 2$ recorded the highest stem diameter and significantly different from plants grown in M3 commercial medium and M4 soil (control) under different water regimes. The performance of $\mathrm{M} 1$ and $\mathrm{M} 2$ could have been due to proportions of peat moss and coconut coir used in the formulation. Inclusion of peat moss and coconut coir in growing medium enhances interaction between growing 
Table 1. Physicochemical properties of soilless and soil-based media.

\begin{tabular}{|c|c|c|c|c|}
\hline Physical properties & M1 & $\mathrm{M} 2$ & $\mathrm{M} 3$ & M4 Soil \\
\hline Bulk density $\left(\mathrm{cm}^{-3}\right)$ & $0.31 \pm 0.01$ & $0.42 \pm 0.01$ & $0.39 \pm 0.01$ & $1.67 \pm 0.32$ \\
\hline Moisture content $\left(\mathrm{g} \mathrm{g}^{-1}\right)$ & $65.3 \pm 0.93$ & $140.3 \pm 0.9$ & $143.45 \pm 0.6$ & $18.13 \pm 0.7$ \\
\hline Total porosity (\%) & $88.3 \pm 0.23$ & 84. $2 \pm 2.73$ & $85.03 \pm 3.1$ & $34 \pm 0.8$ \\
\hline Hydraulic Conductivity $\left(\mathrm{cm} \mathrm{hr}^{-1}\right)$ & $26.2 \pm 0.60$ & $3.6 \pm 0.42$ & $33.50 \pm 0.76$ & $10.28 \pm 0.4$ \\
\hline Saturation $\left(\mathrm{m}^{3} \mathrm{~m}^{-3}\right)$ & $0.8 \pm 0.01$ & $0.7 \pm 0.02$ & $0.79 \pm 0.01$ & $0.32 \pm 0.01$ \\
\hline Field Capacity $\left(\mathrm{m}^{3} \mathrm{~m}^{-3}\right)$ & $0.7 \pm 0.01$ & $0.7 \pm 0.08$ & $0.64 \pm 0.03$ & $0.22 \pm 0.01$ \\
\hline Permanent wilting point $\left(\mathrm{m}^{3} \mathrm{~m}^{-3}\right)$ & $0.4 \pm 0.01$ & $0.3 \pm 0.01$ & $0.44 \pm 0.01$ & $0.14 \pm 0.01$ \\
\hline Available water (\%) & $30 \pm 0.02$ & $40 \pm 0.01$ & $22 \pm 0.01$ & $45 \pm 0.19$ \\
\hline $\mathrm{pH}$ & $5.48 \pm 0.01$ & $5.22 \pm 0.01$ & $6.42 \pm 0.03$ & $4.20 \pm 0.06$ \\
\hline EC $(\mathrm{mS} / \mathrm{cm})$ & $1.45 \pm 0.02$ & $1.83 \pm 0.01$ & $0.60 \pm 0.01$ & $0.57 \pm 0.38$ \\
\hline C.E.C $(\mathrm{cmol} / \mathrm{kg})$ & $43.63 \pm 0.72$ & $39.39 \pm 0.61$ & $34.77 \pm 0.61$ & $20.50 \pm 0.6$ \\
\hline TOC $\%$ & $12.97 \pm 0.27$ & $22.27 \pm 0.64$ & $15.83 \pm 0.52$ & $1.50 \pm 0.06$ \\
\hline $\mathrm{C}: \mathrm{N}$ & $13.67 \pm 0.88$ & $21.00 \pm 0.58$ & $15.67 \pm 0.88$ & $4.33 \pm 0.33$ \\
\hline $\mathrm{N} \quad(\mathrm{mg} / \mathrm{L})$ & $4.73 \pm 0.69$ & $6.47 \pm 0.34$ & $4.10 \pm 0.06$ & $0.13 \pm 0.01$ \\
\hline$P \quad(\mathrm{mg} / \mathrm{L})$ & $0.24 \pm 0.03$ & $4.33 \pm 0.12$ & $0.31 \pm 0.01$ & $23.33 \pm 0.9$ \\
\hline $\mathrm{K} \quad(\mathrm{mg} / \mathrm{L})$ & $0.31 \pm 0.01$ & $0.77 \pm 0.04$ & $3.77 \pm 0.09$ & $0.86 \pm 0.04$ \\
\hline $\mathrm{Ca} \quad(\mathrm{mg} / \mathrm{L})$ & $1.77 \pm 0.04$ & $5.20 \pm 0.11$ & $1.32 \pm 0.01$ & $0.24 \pm 0.03$ \\
\hline $\mathrm{Mg}(\mathrm{mg} / \mathrm{L})$ & $0.30 \pm 0.01$ & $1.40 \pm 0.01$ & $0.21 \pm 0.01$ & $1.57 \pm 0.04$ \\
\hline $\mathrm{Zn} \quad(\mathrm{mg} / \mathrm{L})$ & $0.11 \pm 0.01$ & $0.13 \pm 0.01$ & $9.53 \pm 0.38$ & $0.04 \pm 0.01$ \\
\hline $\mathrm{Cu} \quad(\mathrm{mg} / \mathrm{L})$ & $0.04 \pm 0.01$ & $0.11 \pm 0.01$ & $0.14 \pm 0.01$ & $0.32 \pm 0.24$ \\
\hline $\mathrm{Mn}(\mathrm{mg} / \mathrm{L})$ & $0.33 \pm 0.01$ & $0.31 \pm 0.01$ & $7.72 \pm 0.02$ & $1.16 \pm 0.09$ \\
\hline $\mathrm{Pb}(\mathrm{mg} / \mathrm{L})$ & $0.14 \pm 0.03$ & $0.20 \pm 0.06$ & $0.13 \pm 0.09$ & $0.10 \pm 0.05$ \\
\hline $\mathrm{Cd}(\mathrm{mg} / \mathrm{L})$ & $0.02 \pm 0.01$ & $0.50 \pm 0.06$ & $0.10 \pm 0.05$ & $0.02 \pm 0.01$ \\
\hline $\mathrm{Cr}(\mathrm{mg} / \mathrm{L})$ & $0.77 \pm 0.09$ & $0.60 \pm 0.25$ & $0.20 \pm 0.06$ & $0.22 \pm 0.01$ \\
\hline$B(\mathrm{mg} / \mathrm{L})$ & $0.10 \pm 0.05$ & $0.05 \pm 0.03$ & $0.53 \pm 0.15$ & $0.12 \pm 0.01$ \\
\hline $\mathrm{Fe}(\mathrm{mg} / \mathrm{L})$ & $0.30 \pm 0.06$ & $1.12 \pm 0.01$ & $4.70 \pm 0.06$ & $1.14 \pm 0.02$ \\
\hline
\end{tabular}

$\mathrm{Fe}(\mathrm{mg} / \mathrm{L})$
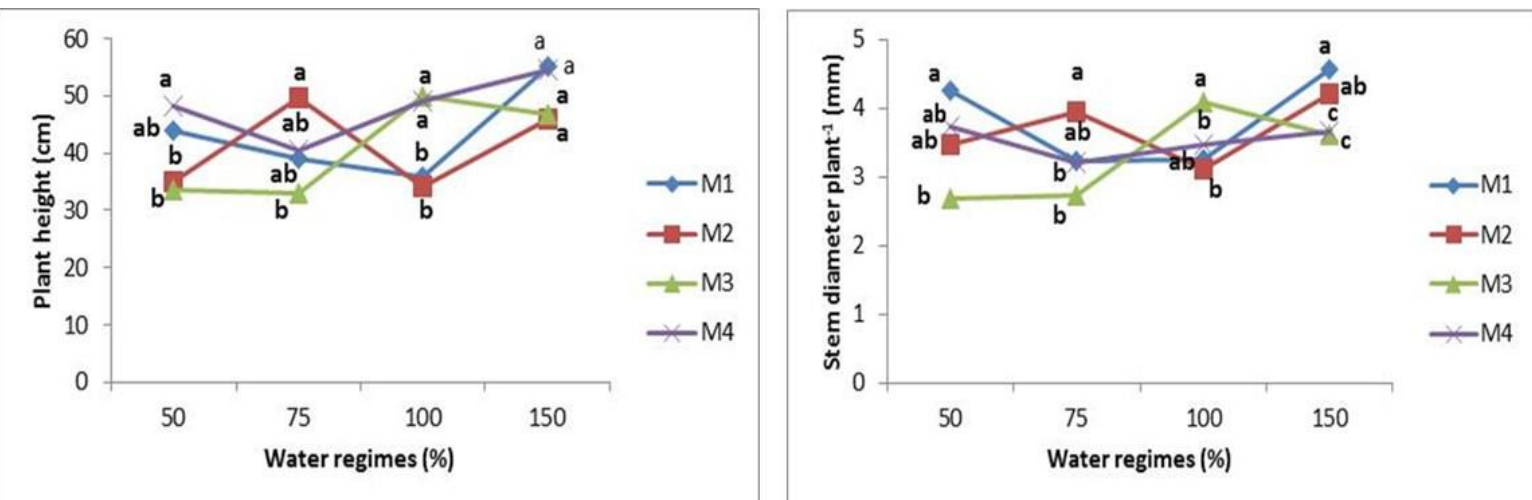

Fig 1. Effect of soil/soilless media and water regimes on the growth of rubber seedlings. Fig 1a and b. Effects of soilless media/soil (M1, M2, M3 and M4) and water regimes on plant height and stem diameter of rubber seedlings. Mean values followed by the same letter are not significantly different at $p<0.05$, based on a least significant difference test (LSD).
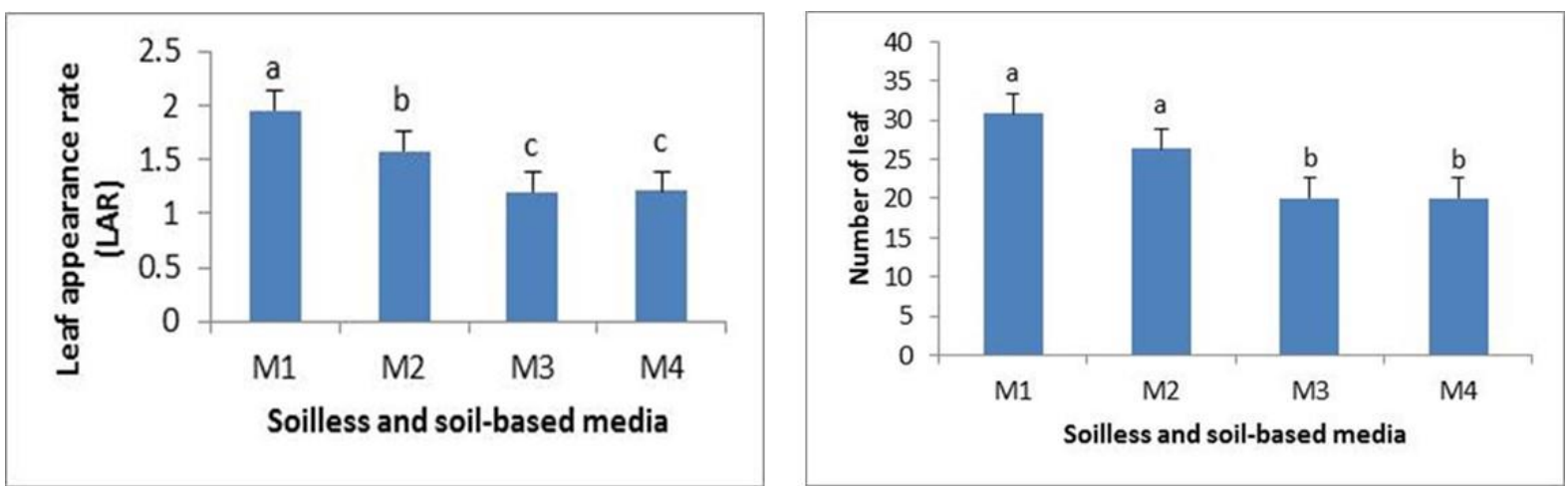

Fig 2. Effect of soil/soilless media and water regimes on the growth of rubber seedlings. Fig $\mathbf{2 a}$ and $\mathbf{2 b}$. Effects of soilless media/soil on leaf appearance and number of leaf of rubber seedlings. Mean values followed by the same letter are not significantly different at $p<0.05$, based on a least significant difference test (LSD). 

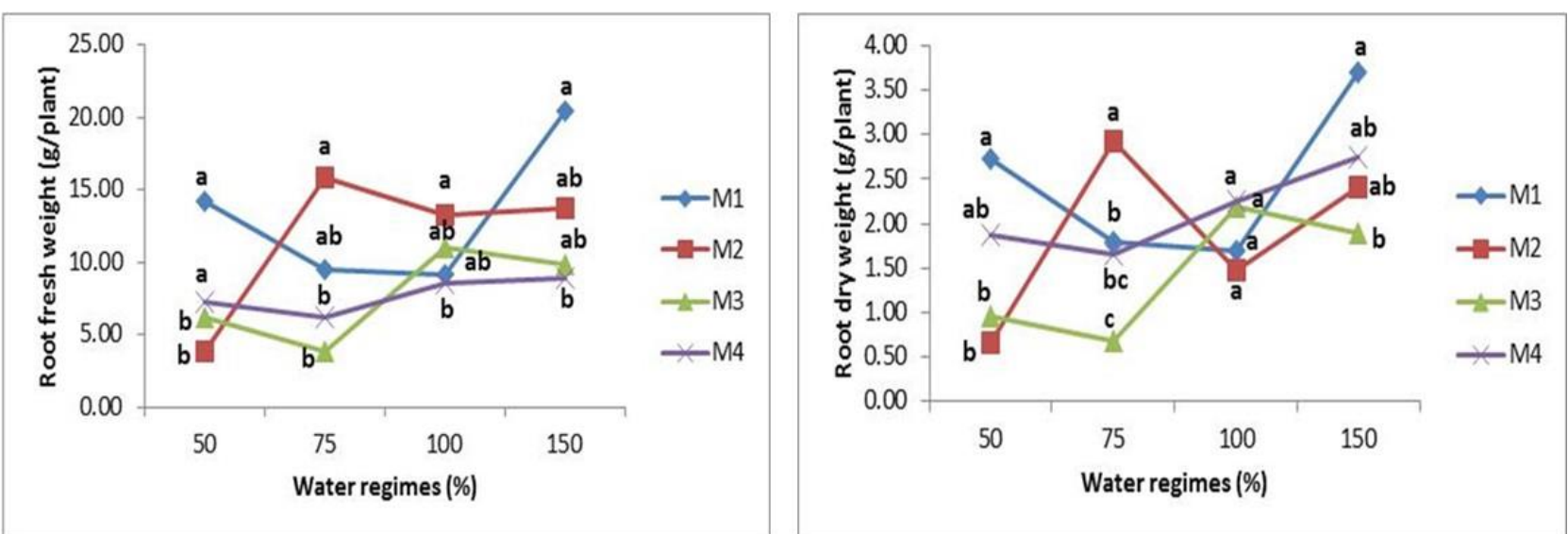

Fig 3. Effect of soil/soilless media and water regimes on the biomass production of rubber seedlings. Fig $\mathbf{3 a}$ and $\mathbf{b}$. Effects of soilless media/Soil (M1, M2, M3 and M4) and water regimes on root fresh weight and root dry weight of rubber seedlings.
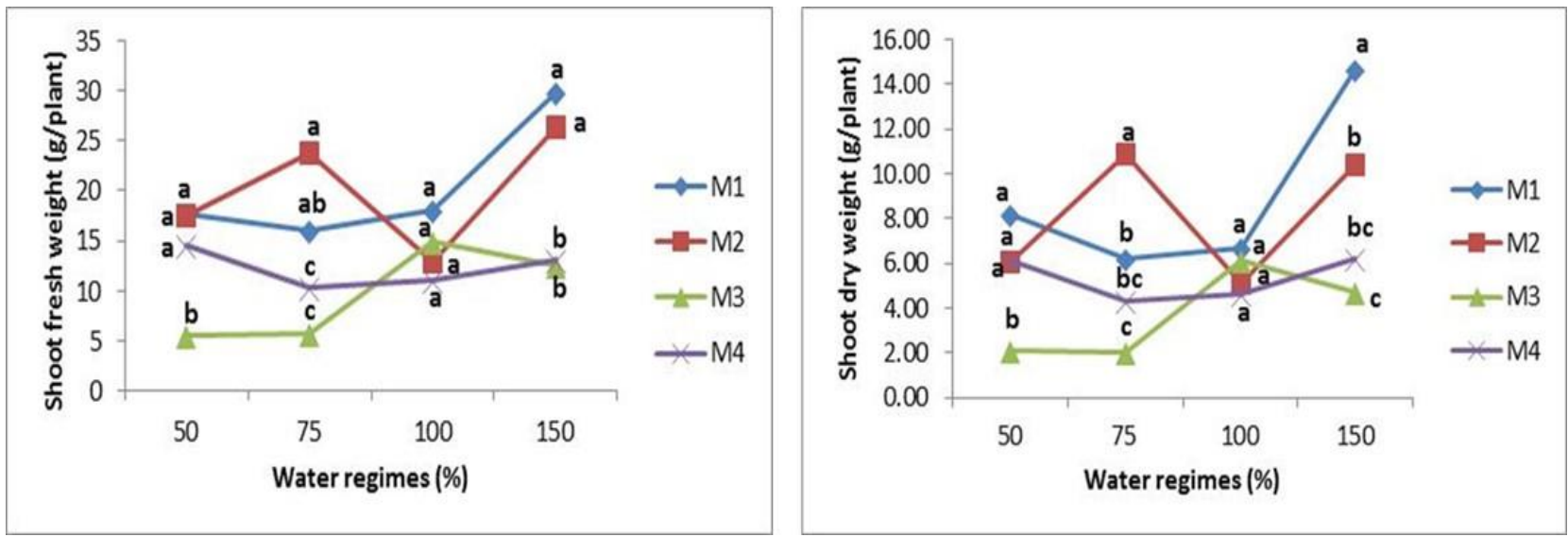

Fig 4. Effect of soil/soilless media and water regimes on the biomass production of rubber seedlings. Fig $4 \mathbf{a}$ and $\mathbf{b}$. Effects of soilless media/soil (M1, M2, M3 and M4) and water regimes on shoot fresh weight and shoot dry weight of rubber seedlings.
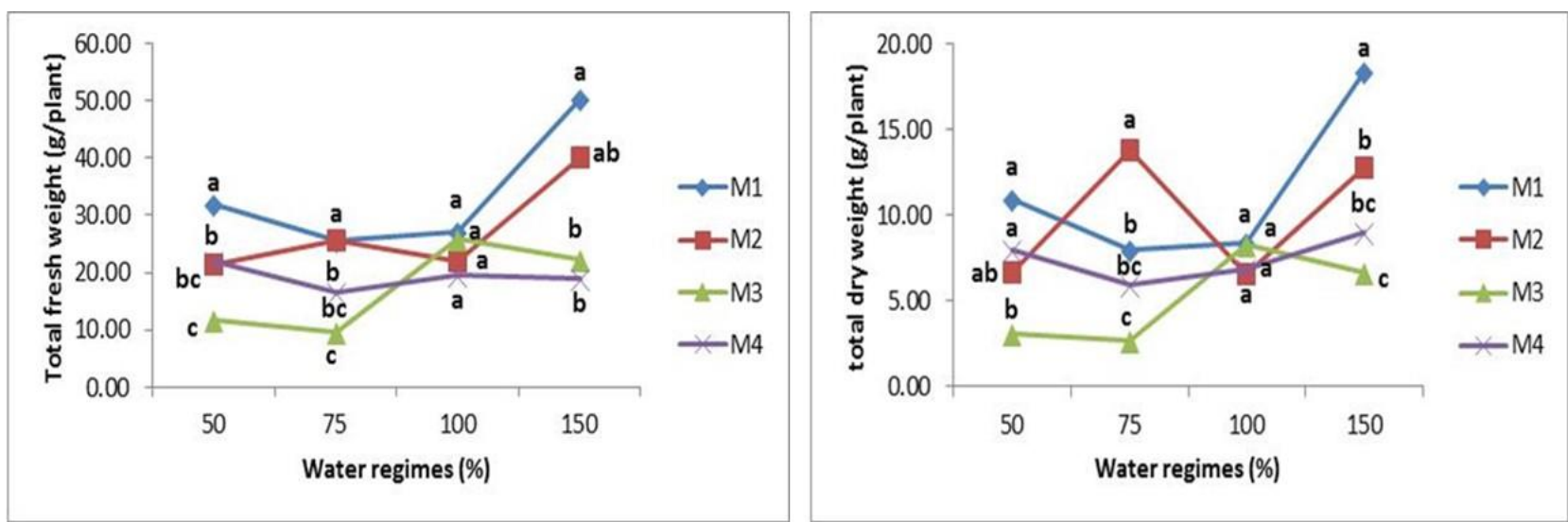

Fig 5. Effect of soil/soilless media and water regimes on the biomass production of rubber seedlings. Fig $\mathbf{5 a}$ and $\mathbf{b}$. Effects of soilless media/Soil (M1, M2, M3 and M4) and water regimes on total fresh weight and total dry weight of rubber seedlings. 

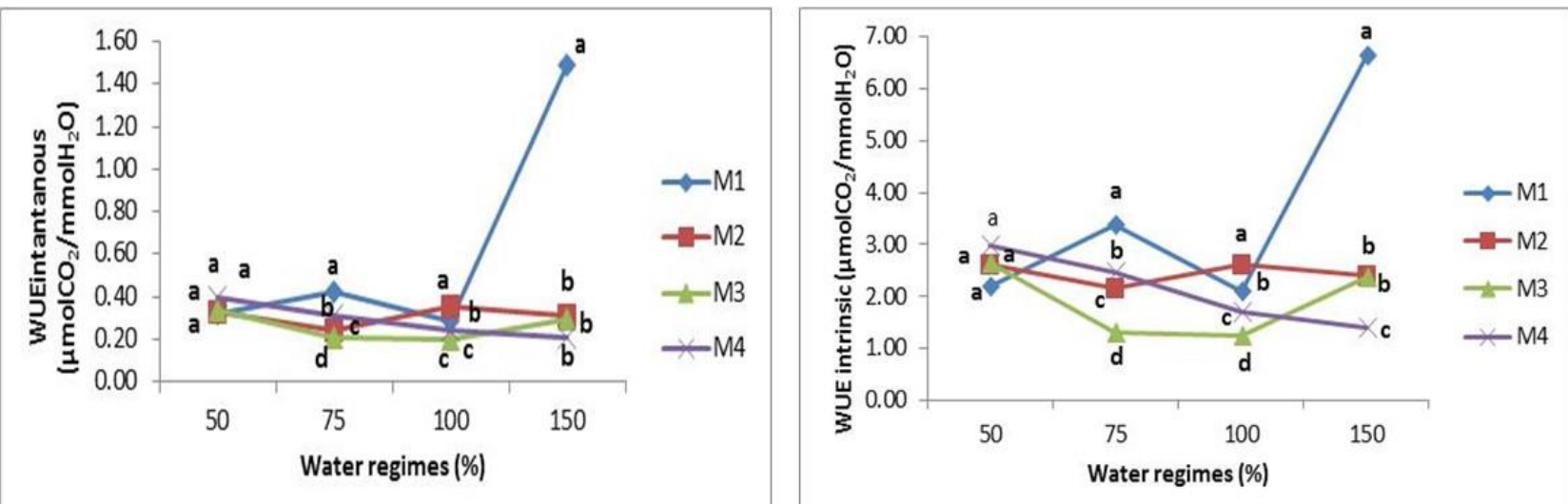

Fig 6. Effect of soil/soilless media and water regimes on the growth of rubber seedlings. Fig $\mathbf{6 a}$ and b. Effects of soilless media/Soil (M1, M2, M3 and M4) and water regimes on WUEinstantaneous and WUEintrinsic. of rubber seedlings. Mean values followed by the same letter are not significantly different at $p<0.05$, based on a least significant difference test (LSD).
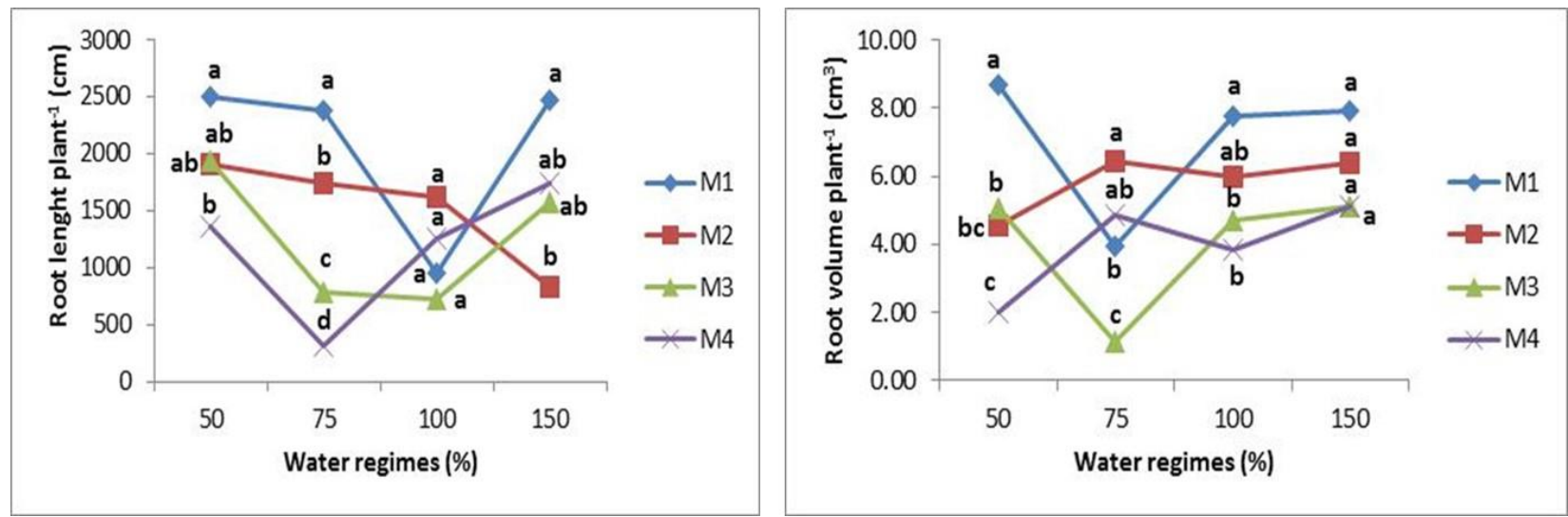

Fig 7. Effect of soil/soilless media and water regimes on the root production of rubber seedlings. Fig $7 \mathbf{a}$ and $\mathbf{b}$. Effects of soilless media/Soil (M1, M2, M3 and M4) and water regimes on root length and root volume of rubber seedlings.
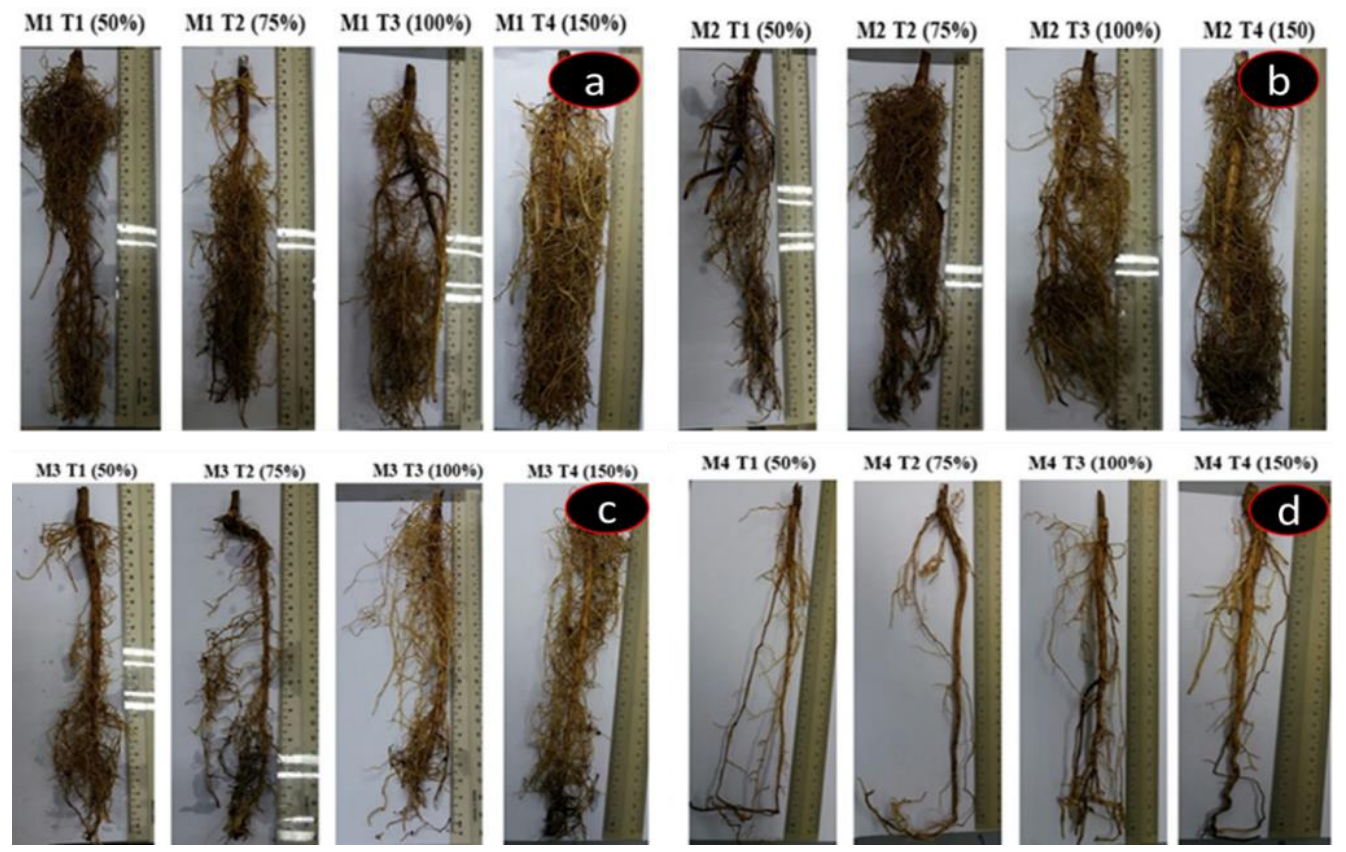

Fig 8. Root patterns of rubber seedlings grown in soilless and soil based media. Fig $\mathbf{8 a}, \mathbf{b}, \mathbf{c}$, $\mathbf{d}$. Effect of soilless $\mathrm{M} 1, \mathrm{M} 2, \mathrm{M} 3$ and $\mathrm{M} 4$ soil (control) and different water levels. (T1, T2, T3 and T4) on root patterns of roots of rubber seedlings. 
medium and water holding capacity (Lichty et al., 2014) and this subsequently aid plant growth.

The soilless M1 which recorded greater value contains vermiculite and perlite. Aeration of soilless medium improves plant growth with an addition of vermiculite and perlite as the former possess moderate water retention and high cation exchange capacity while the latter allows permeability and prevents compaction in growth medium (Orozco et al., 1994). Studies conducted by Butt et al., (2014) had shown that seedlings that were grown in perlite and compost-based medium had greater growth vigor. Plant grown in compostbased growing media increases the number of leaves per plant (Ribeiro et al., 2000). Increased plant biomass like root fresh weight (RFW) and root dry weight, especially for the plants grown in $\mathrm{M} 1$, was recorded at different water level but noticeable when highest water level $150 \%$ was applied. The water level could be maintained for the rubber seedling establishment for M1. Compost and peat moss in the substrate as in (M1) promotes plant growth and may significantly increase the fresh and dry biomass of plants (Grigatti et al., 2007). The trend line showed an increase of biomass including SFW and SDW with increased soilless moisture for the plants grown in M1. Performance of the soilless medium M1 corresponded to the increase in total fresh weight and total dry weight. Growing medium containing coconut coir and perlite, as used in M1, could facilitate plant growth and biomass production because both materials aid air retention capacity of soilless medium (Cantliffe et al., 2007). Results of the soilless media analysis revealed higher total porosity of $\mathrm{M} 1$ and M2 which could have influenced the soilless media performance. Raviv et al., (1986) observed that interaction between water and air content of each moisture level of soilless medium is greatly affected by porosity and this may further have a positive effect on plant total biomass.

Plants grown in $\mathrm{M} 1$ and significantly different from the plants grown in M2, M3 and M4 at different water levels as shown in WUE $_{\text {instantaneous. This could have been due to lower stomatal }}$ conductance in plants. Ashraf and Bashir, (2003) equally observed a relationship between higher photosynthetic rate

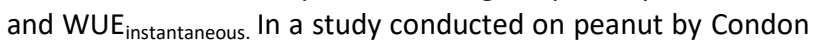
et al., (2002), he reported relationship between $W E_{\text {instantaneous }}$ and photosynthetic which significantly impact plant growth. It was therefore observed that photosynthesis helps in plant water use and impact plant growth as shown in M1. Afwa et al., (2012) observed that when plant receives adequate water, positive response of plant and high yield could be recorded as opened stomatal would be maintained; subsequently positive correlation between photosynthesis rates and transpiration rate which leads to significant plant growth. Noticeably, an increased in $W E_{\text {intrinsic }}$ in the plants grown in the $M 1$ was reported when the highest water level was applied. This indicated a greater increase of stomata conductance than $\mathrm{CO}_{2}$ assimilation rate in the affected media, hence higher plant water use efficiency had occurred (Gozlan and Gutterman, 1999). Thus, this suggests that the plants have developed a mechanism to survive such as resistance to environmental hazards and unpredictable climate. Blum, (2005) noted that the desired crop yield is achieved when crop balanced water use under different water levels in preparation for a limited rainfall and this simply known as moisture reservation. The performance of $\mathrm{M} 1$ was due to combination of materials mixtures like coconut coir, EFB compost and peat moss used in greater proportions providing main physical and chemical property. De Lucia et al., (2013) reported that about 30\% compost in substrate provides the best quality plants.

Root length and root volume were significantly difference among plants grown in different soilless media except for the plants grown in M3 and M4 soil. Root morphological traits could be favored by porosity of a growing medium better than those in soils (Caso et al., 2009). Material composition and physicochemical properties like water content, and porosity may greatly influence differences in plants performance in growing media and noticeable in root growth (Godara and Sharma, 2016). More so root length remains the best when comparing or determining the suitability of a growing medium (Salisu and Noordin 2016). Similarly, porosity and organic nature of a soilless medium as in $\mathrm{M} 1$ and $\mathrm{M} 2$ may equally favour initial root growth (Osmolovskaya and Kuchaeva, 1998). Perlite and vermiculite, when combined with other materials like peat and compost as a soilless mix as in $\mathrm{M} 1$ and $\mathrm{M} 2$, prove superiority over soil-based media especially in initial root growth and subsequently influence plant shoot (Butt and Varis, 2000).

\section{Materials and Methods}

\section{Growing media and physicochemical properties}

Soilless media were used in this experiment. Soilless medium (M1) contains vermiculite $15 \%$, perlite $5 \%$, coconut husk $20 \%$, EFB compose $10 \%$, rock phosphate (CIRP) $5 \%$, peat moss $30 \%$, Urea-N $5 \%$ and Burnt rice husk $10 \%$. Soilless medium (M2) contains vermiculite $10 \%$, perlite $10 \%$, coconut husk $15 \%$, EFB $15 \%$, CIRP $5 \%$, peat moss $20 \%$, Urea $10 \%$ and sugarcane Bagasse $15 \%$. Soilless medium M3 is a commercial medium while Oxisol soil $100 \%$ as control was codded M4. Bulk density was determined as follow; a known volume of each of the media was filled in core ring measuring $7.6-4.0 \mathrm{~cm}$.

The samples were weighed with the core ring. Thereafter, the samples were oven-dry at $105^{\circ} \mathrm{C}$ for about 24 hours. Then the media were weighed with core ring Blake and Hartge, (1986).

$$
\text { Bulkdensity }=\left(\frac{\text { weightofmedia, ovendriedat } 105^{\circ} \circ \mathrm{C}}{\text { Volumeoffreshmedia }}\right)
$$

The moisture content of the respective growing media was determined by deducting the dry weight from the fresh weight of the soilless media/soil and later divided by the oven-dry weight to determine moisture content in $\mathrm{g} \mathrm{g}^{-1}$. The following equation was used to determine the moisture content.

$$
\text { Moisturecontent }=\left(\frac{\text { weightoffreshmedia }- \text { weightofovendrymedia }}{\times 10 \text { weightoffreshmedia }}\right)
$$

The media porosity was determined by oven-dried using the following formula:

Totalporosity $=\left(1-\frac{B d}{P d}\right) \times 100$ 
Where $\mathrm{Bd}$ is the bulk density and Pd is the particle density ( $\mathrm{g}$ $\mathrm{cm}^{-3}$ ). The saturated hydraulic conductivity of both soilless media and the soil was determined by the constant head method as described by Teh and Jamal, (2006).

Basic micronutrients such as $\mathrm{Zn}, \mathrm{Mn}, \mathrm{Fe}, \mathrm{Cu}$, and $\mathrm{B}$ was extracted using modified saturated media extract. In order to prepare one litre of standard solution for the extraction of the chemical elements, $1.97 \mathrm{~g}$ of dry diethylenetriamine pentaacetic acid (DTPA) was transferred into a $1 \mathrm{~L}$ volumetric flask. The $\mathrm{pH}$ and EC of the media and soil was determined separately.

\section{Experimental design and Treatment}

The soilless media were filled in root trainer while the soil was filled in polybag. The treatments consisted four irrigation water levels and four growing media (M1, M2, M3 and M4 soil). Water levels was determined as irrigation water needed for the root zone media to rise to field capacity $\left(I_{100}: 100 \%\right.$, at field capacity) and percentages of water applied to the seedlings in various growing medium were $I_{100} 100 \%$ treatment $\left(I_{50}: 50 \%, I_{75}: 75 \%, I_{100}: 100 \%\right.$ and $\left.I_{150}: 150 \%\right)$ with three replications per water treatment. The water treatments was based on the soilless and soil-based field capacity (FC). The experiment was laid out in randomized complete block design with factorial arrangement $3 \times 4$ with three replications. The total experimental units were forty-eight (48). Leaf appearance rate (leaf day $^{-1}$ plant $^{-1}$ ) was taken by counting the number of green leaves at two weeks interval. The leaf appearance rate was calculated as the differences in leaf number divided by the number of days between the taking of the first and the second counts. Plant height was measured with standard measuring tape $10 \mathrm{~cm}$. Stem diameter of the plants was measured with digital Veneer calliper. All plant fresh biomass were collected and weighed $(\mathrm{g})$ to a constant weight of $0.01 \mathrm{~g}$. For the dry matter (DM), plant tissues were oven-dried at $50^{\circ} \mathrm{C}$ for $48-72$ hours. Water use efficiency instantaneous and water use efficiency intrinsic were determined using the gas exchange measurements (Polley, 2002). These were calculated as follows;

$\mathrm{WUE}_{\text {instantaneous }}=, \frac{A}{E}, \mathrm{WUE}_{\text {intrinsic }}=\frac{A}{\mathrm{gs}}$

The $A$ represents net $\mathrm{CO}_{2}$ assimilation rate and $E$ and $g s$ are the transpiration rate and the stomatal conductance, respectively.

Roots were gently separated from the growing and containers, washed thoroughly with water to remove excess medium. The roots were spread in a transparent plastic tray in a thin layer of water and analyzed for image data. Root morphologies were measured using WinRHIZO pro software (Epson Perfection V700 Photo, Regent Instrument Inc. Canada).

\section{Statistical analysis}

All data were analysed using SAS statistical software Package (Version 9.1). A two-way ANOVA was carried out to determine soilless media/soil and water interaction. Least significant difference (LSD) was used to compare treatment means at the 0.01 and $0.05 \%$ probability levels.

\section{Conclusion}

The soilless media independently performed greatly based on their physicochemical characteristics based on material compositions. Interaction effect on plant growth at different water levels was obvious on growth, biomass yield and root morphological traits of the rubber seedlings. Soilless medium M1 significantly influenced almost all plants growth traits. The performance of this soilless medium was noticeable in plant growth traits like height and stem diameter, vegetative and root morphological traits. It showed a positive interaction with water levels which translated into $W_{\text {instantaneous and }}$ WUE $_{\text {intrinsic }}$ indicating the suitability of the soilless medium for better improvement of rubber seedlings where management and control of irrigation water are considered necessary.

\section{Acknowledgment}

The author would like to thank Universiti Pendidikan Sultan Idris for the support during preparation of the manuscript.

\section{References}

Afwa T, Lachiheb B, Ferchichi A (2012) Drought effect on growth, gas exchange and yield, in two strains of local barley Ardhaoui, under water deficit conditions in southern Tunisia. J Envir Management. 113 (12): 495-500.

Ashraf M, and Bashir A (2003) Relationship of photosynthetic capacity at the vegetative stage and during grain development with grain yield of two hexaploid wheat (Triticum aestivum L.) cultivars differing in yield. Europ J Agron. 19: 277-287.

Blake GR, Hartge KH (1986) "Particle Density," In Methods of Soil Analysis, Part 1: Physical and Mineralogical Methods, ed. A. Klute. American Soci. of Agron., Inc., and Soil Science Society of America: Madison Wis, pp. 377-382.

Butt SJ, Varis S, Ahmad Z, Gurmani AR, Farooqa. (2014) The potential use of soilless and soil based growing media, including grapes residue as an introductory evaluation, for the production of Lactuca sativa L. through bag culture. - Life Sciences Leaflets. 49: 48-60.

Butt SJ, Varis S (2000) Proceeding, 2nd International Symposium on New Technologies for Environmental Monitering and Agro-Application Suitability of containerized rooting media by using bag culture technique for the quality production of crops grown under unheated glasshouse. Eds. Tekirdag: Turkey, pp. 179-186.

Blum A, (2005) Drought resistance, water-use efficiency, and yield potential-are they compatible, dissonant, or mutually exclusive. Crop and Pasture Sci. 56 (11): 1159-1168.

Colombo SJ, Menzies MI, O'Reilly C. (2001) Influence of nursery cultural practices on cold hardiness of coniferous forest tree seedlings. In: Conifer cold hardiness, (eds), Bigras F.J, Colombo S.J. Kluwer. The Netherlands, pp 223-252.

Carles SA, Stowe DC, Lamhamedi MS, Fecteau B, Margolis HA, Bernier PY, Veilleux L, Renaud M, (2005) Turning Off the Tap: Controlling Nutrient Leaching, Growth and Hardening of Containerized White Spruce Seedlings Through Irrigation Management; Forest Research Information Paper N160: Ontario, Canada, pp. 73-78. 
Caso C, Chang M, Delfín AR (2009) Effect of the growing media on the strawberry production in column system. Acta Horticulturea, pp. 843: 373-379.

Cantliffe DJ, Castellanos JZ, Paranjpe AV (2007) Yield and quality of greenhouse-grown strawberries as affected by nitrogen level in coco coir and pine bark media. In: (eds). Proc Flor State Hort Society. 120: 157-161.

Condon AG, Richards RA, Rebetzke GJ, Farquhar GD (2002) Improving intrinsic water-use efficiency and crop yield. Crop Science. 42: 122-131.

De Lucia B, Vecchietti L, Rinaldi S, Rivera, CM. Trinchera A, Rea E (2013) Effect of peat-reduced and peat-free substrates on rosemary growth. J Plant Nutrition. 36(6): 863-876.

Fuller AC, Harhay MO (2010) Population growth, climate change and water scarcity in the southwestern United States. American J Envir Sci. 6(3): 249-252.

Grigatti M, Giorgioni ME, Ciavatta C (2007) Compost-based growing media: Influence on growth and nutrient use of bedding plants. Bioresource Technology. 98(18): 3526-3534.

Godara AK, Sharma VK (2016) Influence of Substrate Composition on Roots and their Categories of Strawberry Plants Grown in Different Containers. Res J Agric Sci. 7(2): 330-335.

Gozlan S, Gutterman Y (1999) Dry storage temperatures, duration, and salt concentrations affect germination of local and edaphic ecotypes of Hordeum spontaneum (Poaceae) from Israel. Biological J Linnean Society. 67(2): 163-180.

Hussain A, Iqbal K, Aziem S, Mahato P, Negi AK (2014) A Review On The Science Of Growing Crops Without Soil (Soilless Culture)-A Novel Alternative For Growing Crops. International J Agriculture and Crop Sciences. 7: 833-842.

Jessy MD, Mathew M, Jacob S, Punnoos, KI (1994) Comparative evaluation of basin and drip systems of irrigation in rubber. Indian J Natural Rubber Research. 7(1): 51-56.

Lieth, JH, Oki LR (2008) Irrigation in soilless production. Soilless Culture: Theory and Practice. USA. Elsevier.

Lichty J, Singleton P, Kim HJ (2014) Proceeding from XXIX International Horticultural Congress on Horticulture: Sustaining Lives, Livelihoods and Landscapes. IHC 2014.
Kirkham MB (2014) Field capacity, wilting point, available water, and the non-limiting water range. (Ed.). In: (eds) Principles of soil and plant water relations Boston: Academic Press, pp. $153-170)$.

Moshelion M, Halperin O, Wallach R, Oren RAM, Way DA (2015) Role of aquaporins in determining transpiration and photosynthesis in water-stressed plants: crop water-use efficiency, growth and yield. Plant, Cell Environment. 38(9): 1785-1793

Miller JH, Jones N (1995) Organic and compost based growing media for tree seedling nurseries. World Bank technical paper, p. 8.

Orozco R, Marfà O, Burés S. (1994) Water status of graded perlites. In: (eds) International Symposium on Growing Media and Plant Nutrition in Horticulture, pp. 137-144.

Osmolovskaya NG, Kuchaeva LN (1998) Proceedings from International Horticulture Conference IHC 25th': Principles of ionic homeostasis in crop growth and quality regulation. Science and Horticulture.

Penot E, Lecomte J (2002) From replantation to diversification: oil palm for rubber smallholders in Indonésia. International Rubber Research and Development Board.

Ribeiro HM, Vasconcelos E, Dos Santos JQ (2000) Fertilisation of potted geranium with a municipal solid waste compost. Bioresource Technology. 73: 247-249.

Raviv M, Chen Y, Inbar Y (1986) Peat and peat substitutes as growth media for container-grown plants. In: (eds) The role of organic matter in modern agriculture Springer, pp. 257287.

Salisu MA, Noordin WD (2016) Effect of fertilizer rates and soil series on root morphological traits and root: shoot ratio of immature natural rubber (Hevea brasiliensis). International Journal Scientific and Engineering Research. 7 (9), 13731378.

Spomer LA (1975) Small soil containers as experimental tools: Soil water relations. Communications in Soil Science and Plant Analysis. 6(1): 21-26.

Teh CBS, Jamal T (2006) Soil Physics Analyses. Universiti Putra Malaysia, Serdang: UPM press, pp. 26. 